Research Article

Luis Alberto Suarez Rojas*

\title{
Between Life, the Curve and the Hammer Blow: Family, Poverty and Abandonment in the Time of COVID-19 in Lima, Peru
}

https://doi.org/10.1515/opan-2020-0112

received July 31, 2020; accepted July 7, 2021.

\begin{abstract}
The COVID-19 pandemic brought anxiety, contagion and death to Peru, which registered 288,477 cases after the first 100 days of the outbreak, leading to a state of emergency. The quarantine measures and mobility restrictions characterized as the "hammer blow" produced significant impacts on the most vulnerable and poor populations across the country. While the Peruvian government implemented a subsidy that augmented social welfare programs, unfortunately many poor families and independent workers were left out. The resulting impact of COVID-19 and the quarantine measures has exacerbated existing inequalities in Peruvian society, particularly along the lines of gender and class. This article uses extensive survey and other data from the city of Lima to analyze the social experience of the pandemic from the perspective of the family, the impact of the pandemic on the domestic economy and household management, and finally the dilemmas of care and routines within families.
\end{abstract}

Keywords: COVID-19, Lima (Peru), Inequality, Gender, Class

The 21st century has brought with it new challenges for the management of epidemics and pandemics, including at least five large-scale infectious disease outbreaks between 2003 and 2015, including Severe Acute Respiratory Syndrome (SARS) (2002-2004), Avian Influenza or H5N1 (2005), Swine Flu (2009-2010), Ebola virus in West Africa (2014-2015) and Zika virus (2015). Of this group the first four were related to zoonosis, or the transfer of a pathogen from animals to humans, a growing area of disease transmission. Notably, the COVID-19 pandemic is the third coronavirus outbreak to have a significant impact on human populations this century, following the aforementioned SARS outbreak and the emergence of Middle East Respiratory Syndrome in 2012. Here, we are reminded of Singer's (2009) warning on the possibility of more epidemics caused by global anthropogenic changes.

Birx (2005) has noted that contemporary anthropology with its holistic perspective is central to understanding and managing the impacts of pandemics. Anthropologists Susser and Lee (2009) have analyzed women's paths of hope, sources of resistance, and growing community activism in response to the HIV/AIDS epidemic. Kleinman and Watson (2006) showed how SARS in China constituted a form of social suffering linked to multiple variables including social stigma. This perspective intertwines various epidemiological, political, economic, social, cultural, and moral aspects, leading to the warning that this pandemic constituted a turning point for humanity. Major and Keil (2011) similarly discussed the experience of SARS in Canada and the role of racialization, suggesting that it was "disorderly gutting" when racialized workers became the public face of the disease. To this we must add Caduff's (2015) emphasis on the relationship between pandemics, fear, anxiety and uncertainty. Singer (2009) builds on the contributions of Lindenbaum (2001) by stressing that understanding epidemics from an anthropological perspective allows for the examination of cultural aspects, institutional forms, social practices and states of mind; furthermore, he underlines the importance of social structures and complex social architectures of inequality as central to the study of epidemics.

Article note: This article is a part of the Special Issue on Pathogenic Politics: Life, Death, and Social Responses to the COVID-19 Pandemic, edited by Theodore Powers \& Jeremy Rayner.

*Corresponding author: Luis Alberto Suarez Rojas, Department of Anthropology, Faculty of Social Sciences, Universidad Nacional Mayor de San Marcos (UNMSM), Lima, Peru, E-mail: Isuarezr@unmsm.edu.pe 
More recently, Kelly, Keck, and Lynteris (2019) consider epidemics as total social phenomena: processes and events that transform social life and produce ruptures in human/non-human relations.

Adopting a critical approach towards this literature, Thiongane (2012) wonders how we can consider an epidemic as an anthropological object when it is in itself an ephemeral event. Instead, the author proposes to analyze epidemics as scenarios where politics, bacteriological expertise, public health and emergency action articulate with one another. Accordingly, Thiongane (2012) analyzes the case of Senegal and Ethiopia emphasizing the role of epidemiological metaphors, policies, and discourse regimes, which are ultimately the result of political and historical processes.

Certainly, the emergent COVID-19 pandemic highlights the critical insights provided by these anthropological accounts provide into the politics and effects of contemporary epidemics. I consider that the pandemic can be approached in the multidimensionality of its impacts by placing the lives of people at the center, that is, their unique and concrete experience of COVID-19. Likewise, we can analyze the domestic economy by highlighting the decisions within households, as well as the flow of money, without leaving aside the structural precarization of life and production of inequality. We can illuminate aspects of families' care strategies, their capacity for agency and the repercussions on familial intimacy, without overlooking variables such as social stigma as warned by Kleinman and Watson (2006). Moreover, as suggested by Thiongane (2012), we can analyze the approach to the pandemic by examining epidemiological metaphors such as "the curve", which refers to the number of cases over time, and the "hammer blow", which suggests measures to control contagion.

This approach to studying the impact of COVID-19 on urban households in Lima underscores how the pandemic exacerbates existing inequalities along the lines of gender and class. Those in precarious social and financial circumstances have been most deeply impacted by the pandemic. Moreover, the additional care work associated with the COVID-19 pandemic, such as the additional labor time dedicated to caring for sick family members or disinfecting household surfaces, was allocated along gendered lines, with the majority of this unpaid work being undertaken by women within households. As such, structural conditions such as gender inequality, poverty, and vulnerability are central to understanding the uneven impact of COVID-19, an analytical focus associated with critical medical anthropologists (Scheper-Hughes, 1992; Farmer, 1992; Baer \& Singer, 1995).

Methodologically, this article presents the results of 60 in-depth interviews applied to representatives of families in Metropolitan Lima, Peru. These interviews were conducted between the months of July and August 2020, during a mandatory quarantine and state of emergency that lasted 100 days. The families interviewed resided in the districts with the highest level of infection and in situations of vulnerability. The interviews were based on a semi-structured, validated questionnaire, and open coding was applied to the results. The statistical data presented is the product of this open coding. I use this data from the interviews undertaken during the period of quarantine to understand the social experience of the pandemic from the perspective of the family, the impact of the pandemic on the domestic economy and household management, as well as the dilemmas of care and changing routines within families.

Building on the base of provided by these interviews, this article analyzes the impact of COVID-19 on family life and the government's response to the social crisis that has accompanied the pandemic in Lima. The article is structured in three parts: in the first, I provided a brief review of the anthropological approach to epidemics and pandemics and the methodology employed by this article. In the following section I provide an overview of the first months of the pandemic in Peru and the public policy context, before proceeding to an analysis of the 100 days of the health emergency, including a brief summary of public health, education, unemployment, the local food supply system, economic recovery policy and the subsidy system. In the third and final part, I present results from the interviews and offer some conclusions.

\section{The Hammer and the COVID-19 Pandemic in Peru}

On March 9, 2020 Italy declared a quarantine in the totality of its territory, even as Latin America continued to receive flights from Asia and Europe. The WHO declared the COVID-19 to be a pandemic two days later, at which point it had already reached 114 countries, infected 118,000 people and caused 4,291 deaths. In Peru, official sources assure that patient zero was registered on March 6: A young pilot of Peruvian origin contracted the virus during his vacations in Spain, France and the Czech Republic. Ten days later, on March 15, 2020, the health emergency and the quarantine 
of the whole Peruvian national territory officially began, as the President and Council of Ministers decreed a state of health emergency and mandatory closure. The SARS-CoV-2 virus thus led the country into a terra incognita, as the national borders were closed and a period of mandatory self-quarantine was imposed.

During the first days of the quarantine, essential services remained open, such as supermarkets, banks, fuel distribution, medicine, cleaning, telecommunications, press and funeral services. According to Peru's quarantine policy, only one person per household was permitted to leave the house to secure food and that person was required to wear a mask and follow disinfection protocols while doing so. To further restrict mobility, the government implemented a curfew in Lima, initially from 8:00 p.m. to 5:00 a.m., subsequently extended from 6:00 p.m. to 5:00 a.m. The quarantine was also extended in other regions such as Loreto, La Libertad, Lambayeque, Piura and Tumbes.

The aim was to flatten the epidemiological curve employing the metaphor of "the hammer", which consisted of the implementation of states of emergency and quarantine in order to avoid the spread of the disease. On paper, these policies aimed to strictly control the movement of the Peruvian population, but they did not have their intended effects. For example, the policy that limited to two the number of persons per household permitted to buy food was not enforced. From April 2, the government decreed that men could go out on Mondays, Wednesdays, and Fridays, while women would be allowed to go out on Tuesdays, Thursdays, and Saturdays. This measure did not work in practice and the government had to later retract it. And although the national police and the army were mobilized to regulate the movement of the population, this did little to stem the tide of infections. By the beginning of May there were already 4,098 people infected by COVID-19 and by June 9,900 infected.

Despite such strict measures, Peruvian authorities were unable to prevent contagion and regrettable deaths. After 100 days of a state of emergency, Peru registered cases of COVID-19 in 18 of the country's 25 regions. In addition, it left a total of 288,477 cases and 9,860 deaths, the majority of which were concentrated in Lima, the national capital. The disjuncture between the country's drastic containment measures and the continued growth of infections led the international press to frame this situation as the "Peruvian paradox". Indeed, while the state imposed the region's most aggressive quarantine, the social effects of two decades of austerity blunted the impact of these measures. While public commentators focused on Peru's stable macroeconomic status, including low levels of public debt, long-term restrictions on social spending by the state and deregulation have led to a growth in informal markets, particularly in urban areas, and increasingly overcrowded poor and working-class urban settlements. The combination of these factors along with the precarity induced by the quarantine itself precluded many in Lima from adhering to the restrictions implemented to counteract the spread of COVID-19.

The pandemic also revealed the critical situation of the nation's hospitals, which are characterized by an insufficient number of medical personnel, supplies, and low quality of health infrastructure, especially in the hospitals in rural areas. At the end of April, according to the Minister of Health, Victor Zamora, Peru had 719 beds in the Intensive Care Units (ICU) for COVID-19 patients nationwide. At that time, 554 were already occupied and 165 available (Radio Nacional, 2020). However, in providing these statistics, the Minister of Health included ICU beds in private clinics. The public hospitals were overcrowded; demand for care quickly overwhelmed public sector capacity and people were treated in overflow areas of these facilities, such as in the corridors. Clearly, systemic underfunding of the Peruvian public health sector exacerbated the impact of the pandemic, with those unable to afford private sector care bearing the brunt of systemic underfunding.

Faced with increasing demand for health services, private health clinics responded by charging exorbitant rates for ICU care. By the end of June, the private clinics wanted to charge up to 97,000 soles $(\$ 27,500)$ for 21 days of care. After the Archbishop of Lima intervened to mediate with the for-profit clinics, they agreed to decrease the cost of treatment to 55,000 soles $(\$ 16,000)$ for 21 days. A lack of public health sector capacity was also evident in one critical area for people infected with COVID-19: the supply of oxygen. In June, several hospitals in Peru announced their total lack of oxygen. Patients' families were therefore forced to buy their own oxygen tanks through private companies. On the market, a 10 -cubic-meter balloon costs between 4,800 soles $(\$ 1,400)$ and 6,000 soles $(\$ 1,700)$ for 25 hours of supply. According to the president of the Council of Ministers, Vicente Zevallos, demand amounted to approximately 21,740 balls of oxygen, 40\% more than ordinary consumption (Gestión, 2020).

The national state of health emergency provoked the suspension of activities in factories, workshops, restaurants, cafés, cinemas, etc. This, in turn, caused many businesses to reduce their staff and in other cases to declare bankruptcy after more than a month of being closed. Along with the extension of the quarantine, the government then decided to implement the "perfect suspension of work" policy for all formal businesses. This measure entailed state financial 
support for companies with no more than 100 workers whose salaries did not exceed 2,400 soles (\$705). This measure allowed the state to partially take over private sector payrolls and provide payments of 760 (\$223) soles to workers in these companies, supporting 107,000 workers in June, 2020. However, informal workers, who were the most impacted by the pandemic, were not included in this policy. Thus, this form of state support did not reach the 12 million people working in the informal sector, distributed in areas such as transportation (80.9\% of the workforce), construction (77\%), and commerce (73.1\%). The most conservative data assures that in Lima 2.3 million people lost their jobs during the pandemic. According to projections by the International Labor Organization, Latin America could have 41 million unemployed by the end of 2020 (OIT, 2020).

In addition to payroll support, the Peruvian state undertook additional measures to disseminate resources to a wide range of households, including the poor, self-employed, those living in rural areas, and state security forces. The Bono 380 "Yo me quedo en casa" ("I remain at home") measure aimed to provide funding to approximately 2.5 million families in, or at risk of falling into, poverty and extreme poverty. The policy provided for two payments of S/380, in total S/760 (\$223) per beneficiary. In addition, the Peruvian state organized an "Independent Subsidy", which was targeted at 800,000 households of self-employed workers, divided into two payments of S/380, for a total of S/760 (\$223) per beneficiary. At the time of writing, 773,288 households have received this subsidy. Further, the state provided a Universal Family Subsidy of S/760 (\$223) for households whose members did not receive any income during the state of emergency. Those on the public or private payroll were excluded from this measure. The COVID-19 support measures also included a Rural Subsidy, which provided a one-time payment of S/760 to 837,000 homes in situations of poverty and extreme poverty in rural areas. Finally, the Peruvian response included a subsidy for police, military, and prison guards. This is a subsidy of S/720 for policemen (PNP), military, and agents of the National Penitentiary Institute (INPE) who provided services during the state of national emergency. It is intended for 119,000 members of the PNP without distinction of rank.

In general terms, however, many families in situations of extreme poverty did not receive the state bonus. As a result, they had to improvise popular kitchens in vulnerable neighborhoods. One of the critical aspects was the filter used to select beneficiary families. All have been received through the banking system, which generated long queues and some disorder. Therefore, those without access to-or accounts with-the formal banking sector were excluded from these measures. Those without recourse to state support continued to rely upon informal markets for access to goods and resources during this period.

State subsidies for businesses also exacerbated inequalities while failing to adequately support small and informal enterprises. In April 2020, the government implemented the "Reactivate Peru" program to benefit companies and maintain the chain of payments. This program placed S/60 billion ( $\$ 15$ billion) as a credit guarantee for private banks to grant loans of up to 10 million soles ( $\$ 2.5$ million). In June, the list of benefited companies was made public, revealing that the INTERCORP group-one of the most powerful corporate conglomerates in Peru-managed to receive $\mathrm{S} / 152$ million (\$38 million) through ten companies. Although a greater emphasis on small and medium enterprises was expected in this context, in practice Peru's largest corporations benefited instead.

Although the population was immobilized, given the limitations on access to state support the local food markets remained open and attracted a large part of the population from the popular sectors of the city. They became spaces for much face-to-face interaction, in the midst of street trading, without protection and without adequate protocols. After the first half of the state of emergency, local governments took sanitary measures and the Ministry of Health (MINSA) tested many local food markets. Hundreds of vendors tested positive, leading to the temporary closure of some of the markets. The local food markets were a weakness in the fight against Covid 19, but they also served as vital resources for those unable to access state support amid national quarantine.

Just as the quarantine and the modes of state support exacerbated existing inequalities, the shift to online learning unequally impacted Peruvian society. The beginning of the state of emergency and quarantine coincided with the start of the school and universities across the country in the remote/online mode. Unfortunately, the poorest sectors have inadequate connectivity, so educational coverage is not assured. In 2019, according to the National Institute of Statistics, only $58.8 \%$ of the country's population aged six and over had access to the internet in their homes (although $81.6 \%$ had access to the internet via cell phone). In the case of the capital only $56.7 \%$ of households in Lima have Internet, highlighting the barriers to education that accompanied the pandemic. 


\section{The Social Experience of the COVID-19 Pandemic Among Families in Lima, Peru}

In order to understand how the dynamics of quarantine, state support, and the COVID-19 pandemic impacted families, a series of in-depth interviews were carried out across metropolitan Lima. In this section, I present the results of 60 in-depth interviews, coming from North Lima (29\%), South Lima (21\%), Central Lima (26\%), East Lima (22\%) and Callao (2\%). The composition of these households included nuclear families (52\%), extended families (36\%), singleparent families $(10 \%)$ and reconstituted families (2\%). All the interviews were transcribed and open-ended codes were created to organize the responses and identify trends that were then expressed in percentage terms. Using this approach, three key areas were identified as central to the social experiences of families during the pandemic. The first is the social experience of the pandemic from the perspective of the household, emphasizing members' measures and perceptions of risk. The second analyzes the impact of the pandemic on the domestic economy by considering the ups and downs of employment, variations in the flow of money, subsidy policies and household management in relation to food and basic services. The third focuses on care practices and family routines, a point that underscores the unequal and gendered impact of the pandemic.

\subsection{Risk, Stigma, and Experiences of COVID-19}

The majority of those interviewed consider their family to be at imminent risk of contracting COVID-19. This is often because a close family member had been infected or died from infection with SARS-CoV-2: of all those interviewed in the sample, $23 \%$ had a case of infection at home. Clearly, perceptions of risk that participants described in their interviews were well founded.

Some of those interviewed, such as Richard, a 25-year-old man from the Callao district of Lima, had initially downplayed the severity and risk associated with the virus. In an interview, Richard described how his thinking had changed due to the death of his father from COVID-19:

Previously I didn't think so, that it was a big risk. But my father has died from the COVID, 1 week ago. When a person passes, it changes completely the way of thinking. I did take care of myself, but I denied much of the alleged exaggeration in the cleaning. Deaths are on the rise, approximately 10,000 people, affecting many families, I still feel that it is a tragedy what happens.

In addition to the lethal impact of the virus and a concomitant shift in attitudes towards the pandemic, there is additional risk presented by health complications associated with age, obesity or other chronic diseases such as diabetes, heart problems, and other health conditions associated with poverty. Given that many of those interviewed had a family member afflicted with one of these conditions, they believed that they were among the most vulnerable. This was clearly expressed by Mariella, a 25-year-old woman from the San Martin de Porres district in Lima, who had multiple family members with conditions that were associated with more severe COVID-19 complications:

The person most at risk is my mom because she has diabetes, high blood pressure, thyroid and a lot of other diseases. She has come out lucky as she says. And we were afraid of this virus, more than for us, for her. And, yes, we got it, but thank God, it didn't hit us as hard as you see on the news. My brother who had asthma, we had to admit him and buy oxygen because there wasn't any in the hospital.

To Mariella's story we must add the concern that some family members are not only at higher risk for severe infection, but that they will also become sicker than others and require additional care and support from other people living within the household. One aspect of the pandemic highlighted in interviews with these families is the management of potentially sick family members at home, which leads to an increase in stress levels, as well as the demands of preparing homes for isolation. On the other hand, families are also aware of the limitations of hospitals, increasing the risk associated with contracting the virus, because they consider that they would not be provided with timely or quality care by the public system, and also lack the resources required to access private sector care providers. As Geraldine, a 22-year-old woman living in a nuclear family household outlined, "There are no stocks in the hospitals, we are practically condemned to die at home." Yet another concern mentioned by the interviewees is the issue of 
mental health, as some considered that the confinement or quarantine was impacting the psychology of its members, influencing the affective climate of the home.

The perception of risk within households was complicated by the stigma attached to contagion, which limited open discussion of this infectious disease. The impact of stigma on families reporting household members who had been infected showed up clearly in the interviews. Sofia, a 44-year-old woman heading a single parent family living in the Villa el Salvador district of Lima, described how stigma led to some members of her community to be ostracized:

In the neighborhood, the neighbors reported that there were two people who died from COVID-19. People no longer wanted to go to their house- "hey don't go there, don't talk to them," that is to say, they take it as forbidden (...) people start to create panic and stigma by saying, "they are infected, there is the virus, don’t go!” (...). I think that we ourselves create the environment of panic, I think that if a person is contaminated, that does not allow one to take such a drastic measure as not speaking to him (...) I think that as long as one assumes responsibility and is calm, it is better, because if you panic, one creates a hostile environment and the security measures do not work, health is altered and one is more prone to contagion.

Sofia's experience was confirmed by another research participant, Pilar, a 26-year-old woman from the Los Olivos district of Lima, who described how her father was stigmatized by his neighbors:

A friend told me that his father got sick, showed some symptoms and corroborated that some neighbors, when they found out, tried to get away, even if they passed by the same street, they went further away.

These experiences of stigma were widespread in Lima, as evidenced by the discrepancies in reported infections and deaths. On the one hand, 55\% of research participants recognized that there had been infections in their own family and $18 \%$ disclosed that they had family members who had died from COVID-19. On the other hand, the same participants reported much lower levels of self-reporting from their friends: only $13 \%$ of research participants recognized that friends had contracted COVID-19 and only $7 \%$ reported that they had a friend who had died from the disease.

Furthermore, when analyzing this pandemic as a social experience we see that $89 \%$ of the families that have had contact with the virus claim to have experienced situations, sensations and emotions of rejection (58\%), fear (24\%), and to a lesser extent marginalization (4\%) and isolation (4\%). Only $9 \%$ report to have been treated by friends and neighbors in the same manner as they had been prior to their infection with the virus.

\subsection{COVID-19 and the Domestic Economy}

As discussed above, the COVID-19 epidemic and subsequent public health response had a devastating effect on livelihoods across Peru. The sample of households interviewed for this paper reflected these socio-economic effects, as $77 \%$ of the families interviewed registered the loss of jobs and a decline in their income. As a result, the economic subsidies provided by the government aroused great interest because the short and medium term economic outlook for many families was negative. However, only $33 \%$ of the 60 families interviewed received a subsidy of some kind, while $67 \%$ of the families did not receive any.

As Lupe, a 25-year-old woman from the Comas district in Lima outlined, the state system for distributing resources led to "chaos":

There was no filter for the distribution of the bonus, it has generated more chaos, more corruption, it is given to those who should not, a total chaos. I think that better than the bonus, it would have been the baskets, the food bag has also been delivered.

There was also inconsistency in the dissemination of social support, as some families received one subsidy and others had received two. According to Carmen, a 40-year-old woman living in the Breña district of Lima, "I used the subsidy for my financial needs, especially for food. The 'I stay at home' subsidy was 380 soles and I received it twice."

Of the $33 \%$ that received a subsidy, a good part (22\%) used it to cover the cost of services such as electricity and water, and others (12\%) prioritized the use of the funds to buy food. However, a common sentiment was that the subsidy, while helpful, was insufficient to meet the material needs of families. Katy, a 28-year-old woman living in an extended family household in the San Juan de Lurigancho district of Lima, stated this point clearly: 
Nobody can live on 700 soles, unless they are a super small family (...) It didn't reach all the people and it was a bad distribution, because people who didn’t need it had access and vice versa.

In general terms, the population interviewed for this project expressed clear dissatisfaction with the amount of the subsidy, the inconsistency in its distribution, and the failures of the state to reach people in need of support.

The uneven and limited distribution of state financial support contributed to an environment where families worked to conserve increasingly scarce resources amid the COVID-19 pandemic. The combined effects of the pandemic, state support, and limited access to work had contradictory effects on access to nutrition. On the one hand, the media had warned about possible food shortages, so many families stocked up with essential supplies. On the other hand, most households lost employment, and in that context $50 \%$ of the families took measures to ration food. As Andrea, a 25-year-old woman living in a nuclear family explained:

Now I'm going to cook only half a kilo of rice, that's a cup and a half. (...). Now everything is a little more expensive, maybe work and money are more valued. Maybe you don’t throw anything away, everything is OK, none of the food is thrown away.

Federico, a 23-year-old man living in a nuclear family confirmed Andrea’s experiences, stating, "My parents get upset when I eat too much lemon or meat, they say it must last us a long time so we don't go to the market so much and we've changed at lunchtime".

However, in relation to services, imposing austerity within households proved to be more difficult. $57 \%$ of the families interviewed were not able to ration basic services such as water, electricity and internet, principally because during the quarantine there are more members in the house studying or working remotely. As Christian, a 23-year-old man living in a single parent family in the Breña district shared:

We're looking at all this water stuff so we don't overspend, there's always plenty coming our way. We had a problem with electricity, it went up more than usual, (...) we are trying to save, turn off all the lights, consume less water, unplug almost everything daily.

Given this situation, $40 \%$ of families say that their consumption habits have changed, trying to consume less, restricting the use of electricity and in some cases prioritizing certain services over others including dispensing with some services altogether. Given the combined effects of state support and rationing measures taken on by households, however, very few families (2\%) reported not being in a position to pay their bills.

Upon entering the quarantine, families had to buy provisions for one or two weeks, buying only those things that were indispensable. Although the government did not decree the closure of local markets, as well as supermarkets, the supply and purchase of cleaning products was a major concern for the families we interviewed: $36 \%$ of the families prioritized the purchase of cleaning products such as disinfectants and bleach, while trying to implement and practice cleaning protocols, as well as using masks. Even those who were initially skeptical of these measures soon adopted them. Rosa, a 27-year-old woman living in a nuclear family in the Villa María del Triunfo district of Lima, shared how her perceptions of these measures changed over time, stating:

At first, I didn't wear a mask because I thought it was a bit exaggerated (...) then I started to wear a mask because most people did and I felt I had to take that measure. I would disinfect my hands, wash with soap and water, disinfect the soles of my shoes, take a shower, change my clothes.

In our conversations with the families, the cleaning and disinfecting routines and the purchase of cleaning products were viewed as very important for protecting their most vulnerable members. For the same reason, $25 \%$ of families indicated that the first thing they did was to abide by the quarantine measure and maintain social distancing, as well as to reduce travel to what was strictly necessary. Children were a particular concern for families, as Beatriz Torres, a 22 year old woman living in a nuclear family, explained:

We have a little six-year-old boy and because of him all kinds of outings were restricted, my brother visited us to play with my other cousins, that was totally cut off, and that was shocking for the family. Actually, we opted for that measure from the beginning, we started with hand washing, distancing ourselves and reducing the number of outings. 
Only $4 \%$ said that at the beginning of the quarantine that they were looking for information on how best to protect both themselves and their families, highlighting the impact of media campaigns such as radio and television on the adoption by households of measures to limit COVID-19 infections. Among the measures most emphasized by the families are disinfection (59\%), which includes general disinfection, cleaning of food, fumigation and changing of clothes; the use of masks in public spaces also stands out as a significant measure (12\%).

These steps were experienced as labor intensive for Katy, a 28-year-old woman living in an extended family household in the San Juan de Lurigancho district of Lima, who stated, "There should be cleanliness in every way, but the fact that we use masks and always use alcohol gel and spray on everything, seems too incredible to me, although necessary to avoid further contagion." However, the perceived necessity of these steps was underscored by Pilar, a 26-year-old woman living in a single parent family in the Los Olivos district of Lima, who lost her father. She stated, "I have a relative who has died, an uncle of mine, that's why we are exaggerating, taking more extreme measures".

Likewise, the families interviewed emphasized measures such as quarantine, food preparation, change of clothes and social distancing. 23\% did not highlight any particular measure undertaken to limit the spread of the virus within their household, but most families agreed that they were necessary. As Mariella, a 25-year-old woman living in the San Martin de Porres district explained:

At first, I did see it as something heavy, as something really extraordinary. (...) You don't know where this virus is and you can get it. (...) The people who live with you, your mom or dad or some neighbor out there, if you don't know that you have the virus you can spread it to others who may have other diseases and end up dying. So, I don't think these measures are exaggerated, especially considering the number of people who are infected and dead.

Reflecting Mariella's experiences, only 10\% of the families thought that the measures were exaggerated, while $87 \%$ considered that they were extraordinary but necessary to avoid contagion.

\subsection{COVID-19, Reciprocity, and Care in Households}

As part of our interviews, we also explored whether quarantine changed the way the family members related to one another. According to the interviews, 14\% considered that their relationships had been mostly unchanged. However, 67 percent felt that there had been positive changes, such as improved communication (19 percent), or that the pandemic had brought them closer together (47 percent). Katy, a 28-year-old woman living in the San Juan de Lurigancho district saw some positive aspects within here household as a result of quarantine, stating: "(This pandemic) has brought us closer together. Before I was more reserved with my things, with my family's things, now we worry more about each other. While there was communication, it was not like now". Katherine, a 21-year-old woman living in the Lurin district, shared a similar perspective:

We weren't used to spending so much time together-each in his own world. And now we live together more, the relationship between us has improved, before it was a "hello", "bye”, "how are you”, and that was it. Now we sit at the table, we talk a lot, it has improved.

Nevertheless, $19 \%$ of families suggested that there are aspects of the quarantine that have negatively impacted their lives. For example, not being able to visit their families (19\%), intra-family tensions and conflicts (7\%) and precariousness (2\%). For Lupe, a 25-year-old woman living in the Comas district, restrictions on mobility have negatively impacted relationships within her extended family:

It has changed a little. My older brother lives near my house, I went to visit him, we watched movies sometimes. Now I can't do that anymore, he lives with my little nieces and my daughter-in-law's mother and she is a certain age and we can't visit them-since the quarantine started, I haven't been there. I feel that the quarantine has destroyed us.

In addition, $34 \%$ of families indicated that they have experienced stress combined to a lesser extent with anxiety, discouragement, irritability. This is followed by the $32 \%$ who considered that they had experienced anxiety, combined with stress and insomnia; while 13\% suggest that they had gone through depression at some point. Only 13\% report having felt normal and calm during the pandemic, highlighting its widespread psychological impact.

The COVID-19 pandemic has also brought with it increased care obligations within households. Among the families interviewed, $13 \%$ suggested that they have provided care for one or two older adults with complications, while $28 \%$ 
of the families indicate that they live with older adults with chronic health problems, such as hypertension, diabetes, asthma, gastritis, osteoporosis, obesity, or tuberculosis. However, most families (59\%) do not report chronic health problems among family members within their homes, highlighting how pre-existing conditions and lack of access to care can contribute to the uneven and unequal impact of infectious disease outbreaks.

Thanks to the in-depth interviews we were able to observe that in general the households had a gendered distribution of roles and tasks that fell primarily on the housewives. These forms of unpaid labor usually included cooking, cleaning and disinfecting, as well as the management of the household. As Nicky, a 22-year-old man living in a single parent family in the San Martin de Porres district indicated:

I'm in charge of cooking, my mom cleans the bathroom, she pours bleach in the living room, the little one cleans the table, my mom takes care of the soaps, she disinfects the beds, she smokes with the eucalyptus (...) We are like little ants, the more united the better.

Thus, the gendered demands of household labor increased for women, while the other members of the household carried out minor activities of a complementary nature. In addition, it should be noted that those who contribute money to the management of the household economy were those most likely to be relieved of household chores. Given the patriarchal nature of the formal labor market in Peru, these factors combined to exacerbate existing gender inequalities within households.

Another significant theme that emerged through data analysis was the role of reciprocity in family life, that is, the ethical sense of mutual help and collaboration. In this context, $35 \%$ of the families interviewed highlight "reciprocity" as an important value in the family, especially in times of pandemic. The notion of reciprocity is associated with the idea of shared tasks, mutual aid and collaboration. According to Rodrigo, a 23-year-old man living in an extended family household in the Ate district:

We have reciprocity and we are conscious of working as a family, as a small society with a small system. So, everyone does a particular job for everyone, whether it's cleaning the room, fixing some cable, pipe or cooking (...) in addition to paying for certain services. We are always on top of it.

Rodrigo's sentiments were shared by Rosa, a 27-year-old woman living in the Villa María del Triunfo district in a household with a nuclear family, who stated:

Well, reciprocity is something that is being learned, more so in this time, because we all have to help each other, it is not the task of one person, it is a joint effort and we must learn to support each other because this virus has taught us to be more empathetic. I believe that more than support, we must prevent.

\section{Conclusions}

This article offers a window into the experience of quarantined families, providing insight on the social experience of the pandemic from the family perspective. The focus of our research is on the impact of the pandemic on the domestic economy and the care practices and routines of families. These experiences should be read in the context of measures such as the State of Emergency and other measures implemented to reduce the spread of COVID-19 and mitigate its impact. These drastic measures taken include social distancing, confinement, quarantine, and the closing of businesses, which form the "hammer" that was intended to hit and flatten the curve of COVID-19 infections.

It is clear that these measures did not have the success that was expected by those who created them, and these policies were strongly criticized by the population. One of the most important reasons why the "hammer" failed to flatten the COVID-19 curve is that confinement, quarantine, and closure of local businesses also caused a contraction in the informal sector, where majority of Peruvians derive their income. The hammer did not hit the curve, but the virus did hit the lives of people and their families during the first phase of the state of emergency.

During the first weeks of the 100-day state of emergency, families were able to cope relatively successfully. However, the precarious socio-economic circumstances that the "hammer" produced began to impact families after the first month, and without access to subsidies, many households had to find new ways to insert themselves into the local economy in order to stimulate the flow of money needed to reproduce their families. In this context, without access 
to government support and the necessary economic resources to endure a long quarantine, many people could not maintain the restrictions and social distancing. For many households this was a substantial challenge and the long quarantine put families on the ropes.

On this point we must say that the reproduction of life is more than economic; it also implies social life itself. For many that we spoke with, this was the Achilles' heel of the Peruvian case. Families had the strong impulse to get together and celebrate the social rituals deeply rooted in the cultural matrix of Peruvian society. On this point, there is no hammer that can stop the weight of social life. For that reason, one of the mistakes in the management of this pandemic was to only consider the biomedical dimension and ignore the social, cultural, and economic factors that rendered the "hammer" ineffective.

But, how to explain the Peruvian paradox? In light of the evidence, we can observe that the pandemic is not only a biological process, it is above all a collective experience. In order to test a response, we must highlight the role of the cultural matrix, which activated certain barriers such as the social stigma linked to COVID-19. Thus, in the first months of the state of emergency, many people kept their symptoms and diagnosis in reserve for fear of rejection and social stigma. This was compounded by the collapse of the public health systems, most notably hospitals, which were used only in very serious cases.

Another aspect that we must take into consideration is the routine of the families. Although respondents emphasized cleanliness as the main measure-such as the use of alcohol, bleach, even changing clothes, and to a lesser extent the use of masks or other protective mechanisms-very few families emphasized social distancing, reduced mobility and limited contact between people as a factor of protection against COVID-19. The reduced emphasis on these measures is in large part a reflection of the difficulties families faced in maintaining their household finances. In fact, after the lifting of quarantine measures, respondents acknowledged that having had contact through social gatherings increased the risk of contagion. A final and critical point is that the combined effects of the pandemic and state policies exacerbated gender inequality within households. As we outlined above, increased demand for care work along with the introduction of new tasks associated with the pandemic, such as additional cleaning and disinfecting, primarily fell on women.

These findings underscore that the pandemic-and the state response-served to exacerbate existing inequalities in Peru. Many of those working in the informal sector were excluded from the financial support offered by the state, due to factors such as the lack of a bank account. In addition, within households, we can observe increased labor demands for women, exacerbated existing dynamics of gender inequality in Peru. On these points, we must ask, if the hammer did not hit and flatten the curve, what-or who-was impacted by the blow that it delivered? Based on these findings, it is clearly poor and working-class households that were shattered by the hammer, and more specifically, women in these households who bore the brunt of the increased labor that these measures entailed.

Acknowledgments: I thank my students of the Anthropology specialty of the Universidad Nacional Mayor de San Marcos for having collected these testimonies. I recognize the committed and meticulous work of Alvaro Elescano, Anais Marcos, Brescia Chalco, Bryan Huaringa, Camila Mayta, Carlos Alegría, Diego Miñán Isidro, Diego Perez Del Rosario, Gabriela Tito, Gonzalo Ruiz, Jorge Soto, Lucero Ortega, Mauricio Cabrera, Mónica Osorio, Nazarena Garay, José Carlos Torres, Nora Carranza, Paola Velarde, Q’ori Gómez, Sebastián Velazco, Yuliana Zevallos Likewise, I thank my research assistant Gabriela Calvo, for her collaboration and support.

Funding Information: Author states no funding involved.

Conflict of Interest: Author states no conflict of interest.

Informed Consent: Informed consent was obtained from all individuals included in this study.

\section{References}

Baer, H., \& Singer, M. (1995). Critical Medical Anthropology. CRC Press.

Birx, H. J. (Ed.). (2005). Encyclopedia of Anthropology: Five-Volume Set. Sage Publications. 
Caduff, C. (2015). The pandemic perhaps: dramatic events in a public culture of danger. University of California Press. https://doi. org/10.1525/9780520959767

Farmer, P. (1992). AIDS and Accusation: Haiti and the Geography of Blame. University of California Press.

Gestión. (2020, May 28). Demanda de oxígeno para pacientes COVID-19 es de 21,740 balones: 40\% más del consumo regular. Gestión. https://gestion.pe/peru/demanda-de-oxigeno-para-pacientes-covid-19-es-de-21740-balones-que-representa-40-mas-del-consumoregular-noticia/

Kelly, A., Keck, F., \& Lynteris, C. (Eds.). (2019). The Anthropology of Epidemics. Routledge. https://doi.org/10.4324/9780429461897

Kleinman, A., \& Watson, J. L. (2006). Introduction: SARS in social and historical context. In A. Kleinman \& J. L. Watson (Eds.), SARS in China: Prelude to pandemic? (pp. 1-15). Stanford University Press.

Lindenbaum, S. (2001). Kuru, Prions, and Human Affairs: Thinking about epidemics. Annual Review of Anthropology, 30(1), 363-385. https://doi.org/10.1146/annurev.anthro.30.1.363

Major, C., \& Keil, R. (2011). SARS and service work: Infectious disease and racialisation in Toronto. In A. Baldwin, L. Cameron, \& A. Kobayashi (Eds.), Rethinking the great white north: Race, nature, and the historical geographies of whiteness in Canada (pp. 107-126). University of British Columbia Press.

OIT (Organización Internacional del Trabajo). (2020). Nota técnica. Panorama Laboral en Tiempos de la COVID-19. Impactos en el mercado de trabajo y los ingresos en América Latina y el Caribe. OIT Americas. https://www.ilo.org/wcmsp5/groups/public/---americas/---ro-lima/ documents/publication/wcms_749659.pdf

Radio Nacional. (2020, April 26). Covid-19: Zamora anuncia 719 camas UCI, 554 ocupadas y 165 disponibles. Radio Nacional. https:// radionacional.com.pe/noticias/politica/covid-19-zamora-anuncia-719-camas-uci-554-ocupadas-y-165-disponibles

Scheper-Hughes, N. (1992). Death without Weeping: The violence of everyday life in Brazil. University of California Press. https://doi. org/10.1525/9780520911567

Singer, M. (2009). Pathogens Gone Wild? Medical Anthropology and the "Swine Flu” Pandemic. Medical Anthropology, 28(3), 199-206. https://doi.org/10.1080/01459740903070451 PMID:20182961

Susser, I., \& Lee, R. B. (2009). Women's Autonomy Combats AIDS in the Kalahari. Anthropology Now, 1(1), 36-42.

Thiongane, O. (2012). La méningite «prise en grippe»? Ethnographie d'une décision au Comité National de Gestion Épidémique du Niger. Anthropologie \& Santé. Revue internationale francophone d'anthropologie de la santé (4). https://doi.org/10.4000/ anthropologiesante.910 